\title{
Analysis of selected performance parameters of a drive unit fueled by biocomponents
}

\author{
Marietta $\mathrm{M}$ arkiewicz ${ }^{1, *}$ \\ IUTP University of Science and Technology, Faculty of Mechanical Engineering, Al. prof. S. \\ Kaliskiego 7, 85-796 Bydgoszcz, Poland
}

\begin{abstract}
The most desirable effect of motorization development is obtainment of high performance power units. Ecological requirements, however, and exhaustibility of the earth natural resources limit the possibilities of self-ignition engines. The study presents analyses of power and torque of a self-ignition engine fueled with mixtures of diesel and fatty acid methyl esters. The tests show that application of a biocomponent additive to diesel fuel slightly reduces the value of power and torque of the tested vehicle. Moreover, as proven by other tests, application of such mixtures causes an increase in the number of components in the exhaust gases and emission of sound generated by a power unit. The study shows only some of the tests performed to reflect significant performance parameters of transport means.
\end{abstract}

\section{Introduction}

A mixture of aromatic, paraffine and naphthalene hydrocarbons which are emitted from petroleum in the process of distillation, is a fuel used for powering of self-ignition combustion piston engines [1]. The process of petroleum distillation allows to separate its particular fractions depending on the substance boiling temperature. Rectification of petroleum in temperature $300^{\circ} \mathrm{C}$ allows to obtain pure diesel fuel which is further subjected to the processes of reforming and isomerization [1]. This is a standard mixture used for powering of self-injection engines. The limitations associated with availability of natural resources made people start searching for alternative fuel sources. According to the results of tests performed by many other authors biofuels are suitable for self-ignition engine powering. Plant oils are commonly used for production of biofuels. The fuels of plant origin include: rape oil, sunflower oil, soya oil, peanut oil and animal fats [2]. These biofuels must be subjected to chemical treatment to obtain properties similar to the diesel fuel. Due to technical, economic, structural and technological factors this is the rape oil that is most commonly used. Biogas produced from fruit, vegetables and meat waste can also be used for powering of self-ignition engines [3]. Alternative fuels made from products unfit for consumption are referred to as second generation fuels. Microalgae, that is, algae whose cultivation requires only carbon dioxide and solar energy, are another source to be used as biofuels [4]. Also municipal and sewage waste can be used for production of biofuels [5]. The above listed biofuels can protect the environment and provide alternative solutions in the sector of transport. Due to wide availability and low manufacturing and processing costs, the most popular plant oils are transesterified rape oils (fatty acid methyl esters). Numerous tests that have been performed in scientific and industrial centers all over the world have proven that the physical chemical properties of fatty acid methyl esters are most similar to the properties of diesel fuel which makes them the most suitable fuels from renewable sources. Tests of performance parameter characteristics of self-ignition engines powered with plant oil or a mixture of fatty acid methyl esters have been conducted

* Corresponding author: marietta.markiewicz@utp.edu.pl 
in many domestic and foreign scientific centers. Analyses of the test results deal with the problems connected with application of plant oils in fueling combustion engines $[6,7]$. The tests of biocomponent fueled power units, were focused on the engine major performance parameters such as: power, torque, fuel consumption, smoke and exhaust fume toxicity [8, 9]. Literature provides results of numerous fuel consumption tests whose authors report an increased demand for fuel containing a mixture of diesel and fatty acid methyl esters to power self-injection engines [10,11]. Fueling diesel engines with fatty acid methyl esters provides reduction in other exhaust gas components such as carbon oxides, hydrocarbons and particulates $[12,13,14,15,16,17,18]$. The literature analysis shows that fatty acid methyl esters are considered to be liquid fuels, which in the form of a mixture with a diesel fuel, are used for self-ignition engine powering. Assuming that there is no negative effect on the engine performance, many manufacturers allow mixtures of diesel with fatty acid methyl esters to be used for engine powering. These mixtures are referred to as B5, B10 or B20 biofuel which means that the maximal share of a bicomponent should not exceed $20 \%$. Application of methyl esters of plant oil was normalized by the European Union legal regulations. According to the regulation the share of biocomponent can be no more than $10 \%$ in relation to the share of diesel fuel.

The goal of the tests was to compare selected performance parameters of a self- ignition engine with mixtures of diesel fuel and fatty acid methyl esters.

\section{Research object and research materials}

A self-injection rated engine of $81 \mathrm{~kW}$ power with a turbocharger and a diesel common rail injection and electromagnetic injectors was used for the tests.

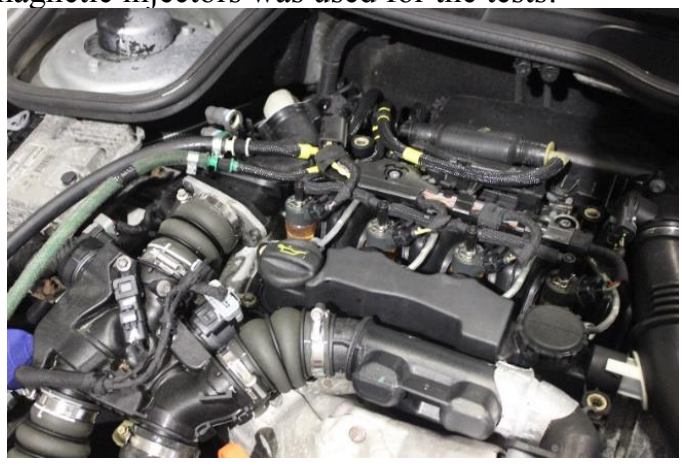

Fig. 1. Self -injection diesel engine.

Combustion engine 1.6 HDI is a power unit widely used in agriculture and automotive industry, in vehicles whose maximum authorized mass up to $3.5 \mathrm{t}$. The characteristics of technical parameters of the considered unit are presented in table 1.

Table 1. Technical characteristics of a power unit.

\begin{tabular}{|c|c|}
\hline Production year & 2005 \\
\hline type & High pressure \\
\hline power & $80 \mathrm{kw}$ \\
\hline Engine cubic capacity & $1560 \mathrm{~cm}^{3}$ \\
\hline Maximal torque & $240 \mathrm{Nm}$ for $1750 \mathrm{rev} / \mathrm{min}$ \\
\hline Number of cylinders & 4 \\
\hline Cylinder arrangement & Row arrangement \\
\hline Number of valves & 16 \\
\hline Injection type & Direct common rail \\
\hline DPF & no \\
\hline
\end{tabular}


The vehicle used in the tests was chosen due to its popularity, possibility to adjust injection parameters, resistance to possible adverse effects caused by the fuel mixture. The vehicle was modified to adjust it to fuel exchange without the necessity to empty the tank. The exhaust system was also modified to make it possible to fix a fume analyzer probe and particulate counter in front of the catalyzer and the exhaust system (the vehicle is not equipped with a diesel particulate filter).

Fatty acid methyl esters and 'pure' diesel fuel ON were used in the tests. The word 'pure' stands for diesel fuel with no additives. The proportions of the proposed mixtures are presented in table 2 .

Table 2. Proportions of the mixtures used for tests.

\begin{tabular}{|c|l|c|}
\hline No. & \multicolumn{1}{|c|}{ Mixture composition } & Mixture marking \\
\hline 1 & Diesel fuel & ON \\
\hline 2 & $70 \%$ of diesel fuel $30 \%$ of fatty acid methyl esters & BIO30 \\
\hline 3 & $50 \%$ of diesel fuel $50 \%$ of fatty acid methyl esters & BIO50 \\
\hline
\end{tabular}

Apart from diesel fuel, the material used in the tests were plant oils after transesterification involving chemical exchange of glycerin bound in a triacylglycerol particle with an added methyl alcohol, in the presence of a base or acid catalyzer, commonly referred to as biocomponents.

\section{Research methodology}

The tests were conducted using the method of laboratory experiment during which the experimental factor was under control so that the experiment would be carried out according to the plan. Measurement of the self-ignition engine power and torque values was performed on a chassis dynamometer depicted in figure 2. A vehicle with 1.6 HDI engine, was put on the dynamometer rollers and fastened to the base with belts, It was accelerated to reach appropriate speed. The measurement was taken under full loading of the immobilized research object. Based on the tests, values of power and torque were determined. An analyzer of the amount of exhaust gas components was connected to the vehicle.

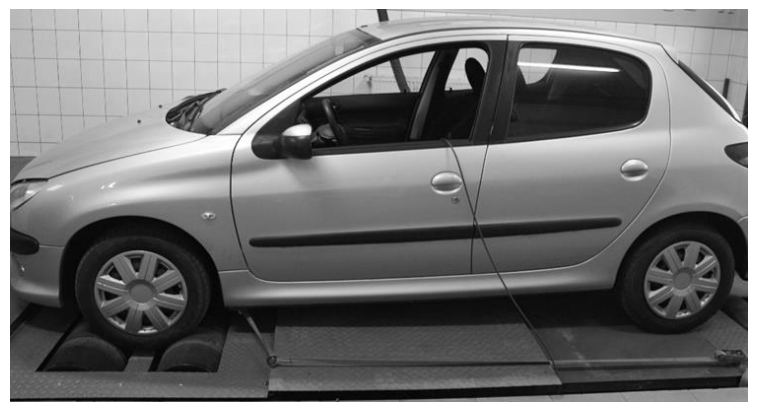

Fig. 2. A vehicle mounted on a chassis dynamometer.

\section{Test results}

The tests were carried out for three fuel mixtures: 'pure' diesel, mixture of $70 \%$ of diesel and $30 \%$ of fatty acid methyl esters and $50 \%$ of diesel and $50 \%$ of fatty acid methyl esters. Performance parameters such as power and torque were measured for the research object (a vehicle equipped with an self-ignition engine) fueled with the analyzed mixtures. 
Each measurement performed on the chassis dynamometer was repeated 30 times. The mean results obtained from measurements are presented in table 3. Figures 3-4 show graphic interpretation of the results obtained from measurements of the research object selected parameters.

Table 3. Results for performance parameters.

\begin{tabular}{|l|c|c|c|c|c|c|}
\hline & \multicolumn{2}{|c|}{ Diesel } & \multicolumn{2}{c|}{ BIO30 } & \multicolumn{2}{c|}{ BIO50 } \\
\hline & power & torque & power & torque & power & torque \\
\hline mean [KM] & 103.56 & 243.72 & 100.99 & 239.49 & 100.15 & 233.59 \\
\hline $\begin{array}{l}\text { mediana } \\
\begin{array}{l}\text { Standard } \\
\text { deviation }\end{array}\end{array} 103.45$ & 24.8 & 100.9 & 239.75 & 100.3 & 234.35 \\
\hline $\begin{array}{l}\text { Variability } \\
\text { coefficient }\end{array}$ & 1.207 & 0.359 & 0.394 & 2.636 & 0.833 & 2.905 \\
\hline minimum [KM] & 102.8 & 243.0 & 100.2 & 235.1 & 96.3 & 228.3 \\
\hline maximum [KM] & 109.9 & 244.2 & 101.7 & 244.2 & 100.8 & 237.6 \\
\hline
\end{tabular}

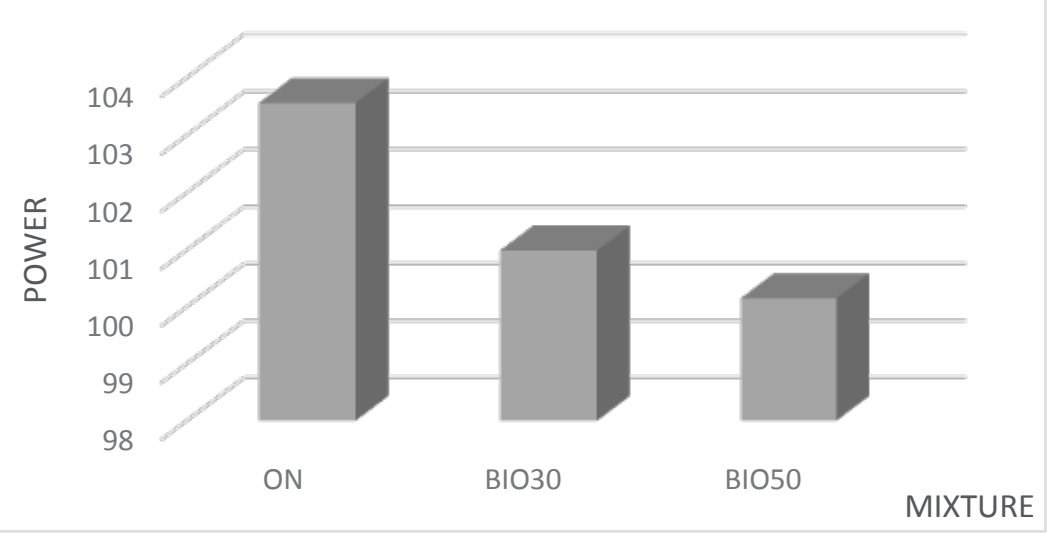

Fig. 3. Results for power.

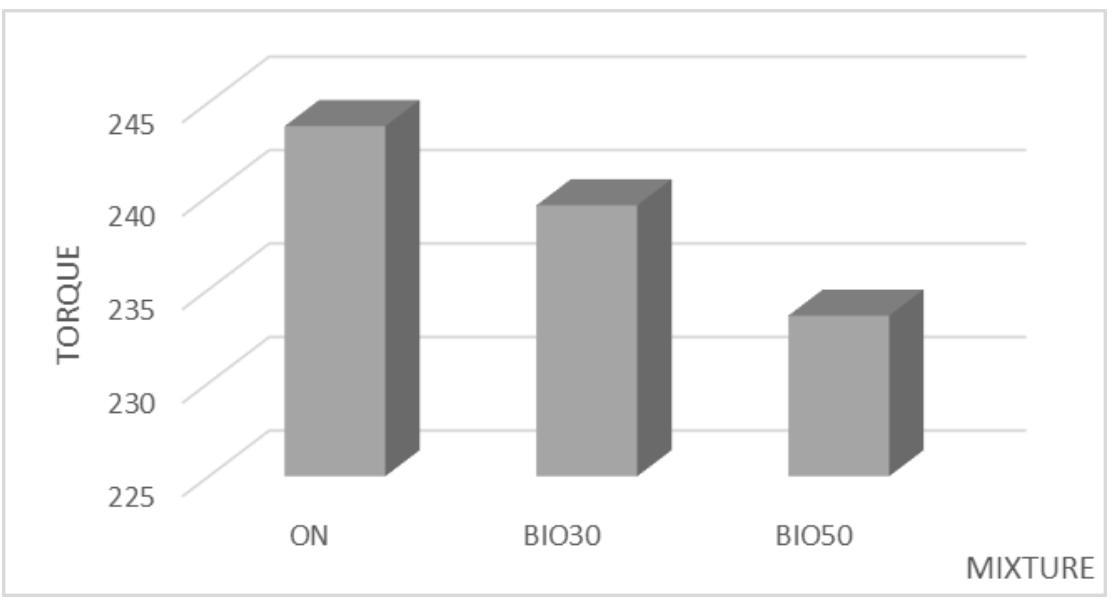

Fig. 4. Results for torque. 
During each measurement performed with the use of a load bearing chassis dynamometer, the electronic system of the device, apart from numerical results, generated a diagram of power and torque measurement, for maximal engine load. The diagram of measurements performed for the analyzed fuel mixtures is presented in figures 5-7.

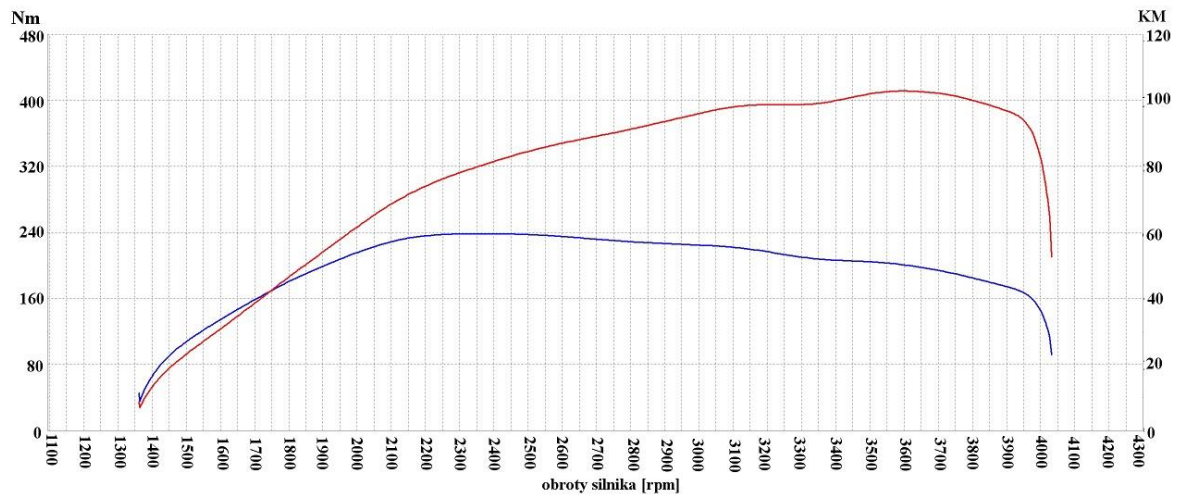

Fig. 5. Characteristics of an engine fueled with diesel mixture.

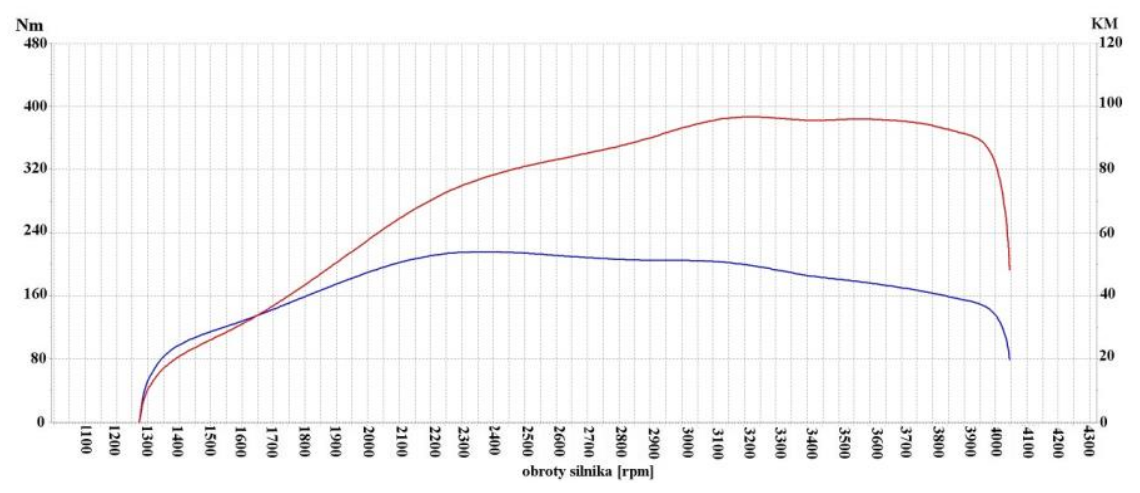

Fig. 6. Characteristics of an engine fueled with BI030 mixture.

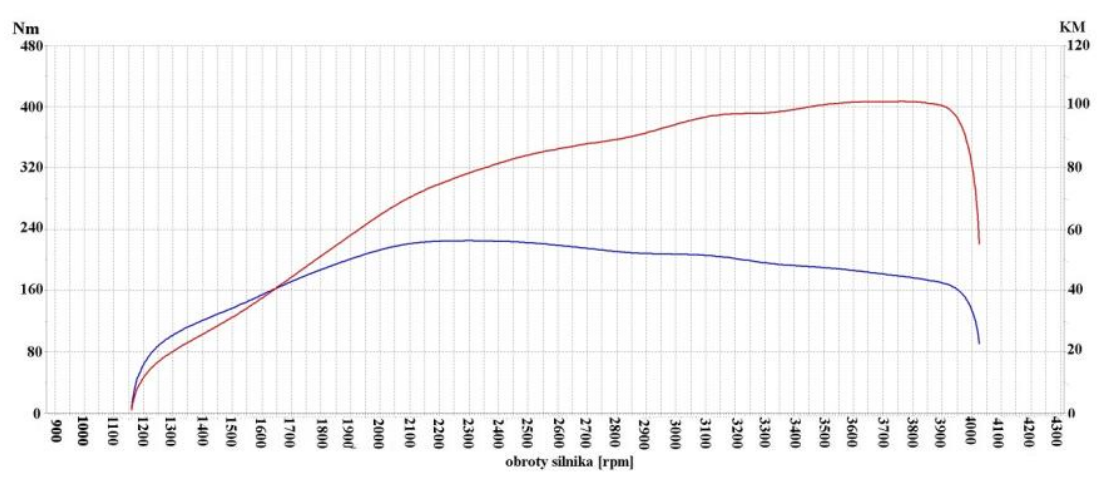

Fig. 7. Characteristics of an engine fueled with BIO50 mixture.

A statistical analysis was performed in order to obtain information on dependencies between fuel mixtures. In the first step a test was carried out to compare the mean values of the three analyzed mixtures. Each test involved examining the performance parameters and torque. The test results confirmed that there was no reason to reject the mean value equality hypothesis. The analyzed population was a 150 element sample $n$, which provided 
the analyzed $\mathrm{x}$ and $\mathrm{y}$ characteristics with definite measurement results. The amount of fatty acid methyl esters added to diesel fuel was marked as y, and the results of tests of particular performance parameter values were marked as y. Thus, in the regression analysis, the percentage share of fatty acid methyl esters in diesel fuel must be considered as independent variables and particular values of the power unit performance parameters as dependent variables. Interpretation of a regression function for engines powered with alternative fuels involves determination of usefulness of particular variables in the statistical model for prediction of the level of dependent variables. The study presents an exemplary regression equation for power and mixture. A regression straight was formed by plotting the obtained empirical points onto the diagram. A diagram of the analyzed linear regression is presented in figure 8 .

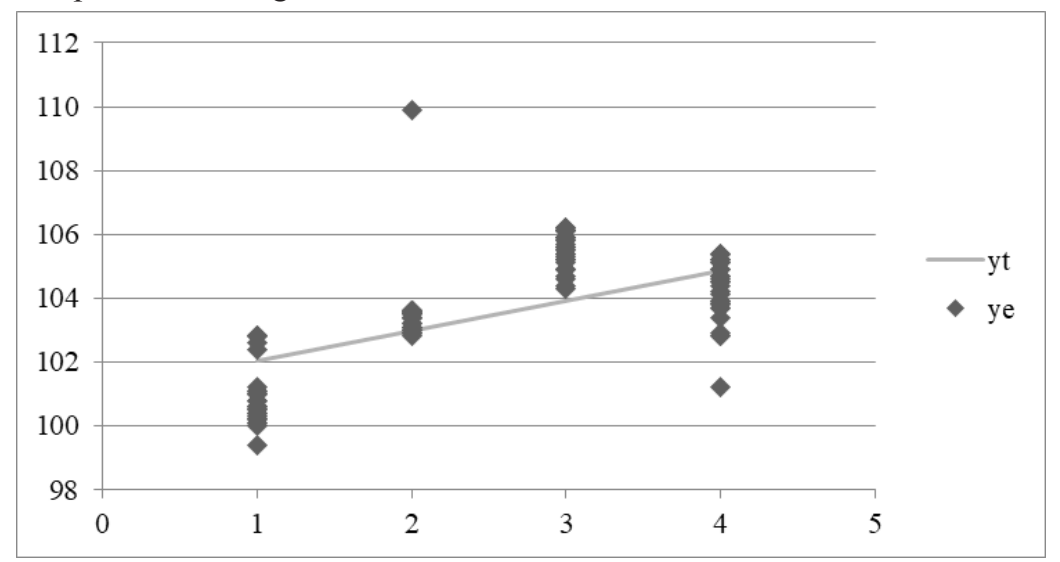

Fig. 8. Linear regression diagram.

The above diagram shows empirical points marked as ye, along with regression straight yt determined for theoretical parameters.

The values of estimators $a$ and $b$ were determined by the method of the smallest squares. Differences between the measurement values and their mean value and the values of determined functions were calculated as well. Based on this, a regression straight was estimated in the following form:

$$
y=0.944 x+101.074
$$

Correlation coefficient for the above regression equation was $r=0.7097$. Testing hypothesis $\mathrm{H} 0$ : $\mathrm{a}=0$ yielded $\mathrm{p}<0,0001$, which means that the dependence in question is statistically significant.

\section{Conclusions}

A search for providing transport means with new fuel solutions is the effect of the restrictions imposed on petroleum extraction and legal regulations. A directive of the European Union imposes application of $10 \%$ of biocomponent additive to diesel fuel, which according to motor vehicle manufacturers, has no negative effect on a combustion engine performance. The presented analysis of test results of performance parameters conducted for power units fueled with mixtures of diesel fuel and fatty acid methyl esters shows a slight drop in the value of power and torque, depending on the biocomponent content in diesel fuel. The test results obtained for 'pure' diesel were assumed to be the reference point. When comparing the results obtained for BIO30 and BIO50 mixtures with the reference point, a drop in power by $2.5 \%$ was found for BIO30 mixture and by $3.2 \%$ for $\mathrm{BIO} 50$ mixture. A drop by $1.7 \%$ was reported for torque in the case of $\mathrm{BIO} 30$ mixture and 
by $4,2 \%$ for BIO50 mixture. Based on the analysis of the test results, it can be found that a mixture of $70 \%$ of diesel and $30 \%$ of fatty acid methyl esters is the best for maintenance of a power unit performance efficiency.

\section{References}

1. Agarwal A., Biofuels (alcohols and biodiesel) applications as fuels for internal combustion engines, Progress in Energy and Combustion Science, V olume 33, Issue 3 (2007)

2. Bajor K., Biernat $K$., Biofuels as alternative energy carriers in internal combustion engines, classification and development prospects, A utomotive A rchive , No 1 (2011)

3. Wierzbicki S., Biogas as a fuel for diesel engines, Jurnal of $K$ ones Powertrain and Transport, V 0. 19, N o. 3 (2012)

4. Singh J., Commercialization petential of microalgae for biofuels production, Renewable and Substainable Energy Revews, vol. 14 (2010)

5. Singh A., Nigan P., M urphy J., Renewable flues from algae: an answer to debatable land basad fuels, Bioresource Technology, vol. 102 (2011)

6. Banapurmath N., T awari P., Hosmath R., Performance and emission characteristics of a DI compression ignition engine operated on Honge, Jatropha A nd sesame oil methyl esters, Renewable Energy, V ol. 33 (2008)

7. Ghobadian B., Rahimi H., Nikbakht A., Najafi G., Y usaf T., Diesel engine performance and exhaust emission analysis using waste cooking biodiesel fuels with an artificial neural network, Renewable Energy, V ol. 34 (2009)

8. Banapurmath N., Tawari P., Hosmath R., 2008, Pperformance and emission characteristics of a DI compression ignition engine operated on Honge, J atropha And sesame oil methyl esters, R enewable Energy, V ol. 33 (2008)

9. Naik S., Goud V., Rout P., Dalai A., Producyion of first and second generation biofuels: a comprenensive review, Renewable and Sustainable Energy Reviews, Vol. 14 (2010)

10. Zivkovic S., Veljković M., Environmental impacts the of production and use of biodiesel, Environmental Science and Pollution Research. No 25 (2018)

11. Lie X., M upondwa E., Life cycle assessment of camelina oil derived biodiesel and jet fuel in the Canadian Prairies. Science of The Total Environment, No 481 (2014)

12. M an X., Cheung C., N ing Z., W ei L., Huang Z., Influence of engine load and speed on regulated and unregulated emissions of a diesel engine fueled with diesel fuel blended with waste cooking oil biodiesel. Fuel. No 180 (2016)

13. Chauhan B., Kumara N., Chob H., Limc H., A study on the performance and emission of a diesel engine fuel ed with Karanja biodiesel and its blends. Energy, No 56 (2013)

14. Markiewicz M. Muślewski Ł., Pająk M., Impact Of Biocomponent Additive To Diesel Oil On Values Of Elected Functional Parameters Of Transport M eans, Polish Journal Of Environmental Studies, Vol. 29 (2020)

15. Markiewicz M., Muślewski Ł., Survey performance and emission parameters of diesel engine powered by diesel oil and fatty acid methyl esters using fuzzy logic techniques, Fuel, V ol. 277 (2020)

16. Markiewicz M., Muślewski Ł., The Impact Of Powering An Engine With Fuels From Renewable Energy Sources Including Its Software Modification On A Drive Unit Performance Parameters, Sustainability, V ol. 11 (2019)

17. Correa S., A rbilla G., Carbonyl emission in diesel and biodiesel exhaust, A tmospheric Environment, V ol. 44 (2008)

18. A garwal A. K., Srivastava D. K., Dhar A., M aurya R. K., Shukla P. CH., Singh A. P., Effect of fuel injection timing and pressure on combustion, emissions and performance characteristics of a single cylinder diesel engine, Fuel, Vol. 111 (2013) 